\title{
Analysis of Household Electricity Consumption Patterns and Economy of Water Heating Shifting and Saving Bulbs
}

\author{
Argo Rosin, Tallinn University of Technology, Taavi Moller, Tallinn University of Technology, \\ Madis Lehtla, Tallinn University of Technology, Hardi Hoimoja, Tallinn University of Technology
}

\begin{abstract}
This article analyses household electricity consumption based on an object in Estonia. Energy consumption of workday and holiday by loads (including high and low tariff energy consumption) is discussed. The final part describes the evaluation of profitability of common investments of consumption shifting and replacing inefficient devices with more efficient ones. Additionally it describes shifting problems and shifting equipment profitability in real-time tariff system.
\end{abstract}

Keywords: energy management, home appliances, pattern classification, energy efficiency, energy storage, profitability

\section{INTRODUCTION}

According to a report by the U.S. Department of Energy in 2008 [1], 74\% of the nation's electricity consumption occurs in buildings. This represents $39 \%$ of the total energy consumption among all sectors. There are two general approaches for energy consumption management in buildings: reducing consumption and shifting consumption [2]. The former can be done through raising awareness among subscribers for more careful consumption patterns as well as constructing more energy efficient buildings [3]. It is different DSM (demand-side management) systems for loads priority based scheduling [4, 5, and 6], which feasibility is questionable. For small customers/households exists very simple and fast profitable solutions for energy consumption costs reducing (for example in household device integrated scheduling functionality), just before the investments must be analyzed consumption patterns.

Electricity consumption in the households and the service sector in Estonia makes up about $62 \%$ of the total consumption. Electrical energy consumption of households is about $27 \%$ of the total energy consumption. Use of the multitariff system with large tariff differences is a major factor in changing customer habits and behaviour. It is important to take into account all the preferences of a customer, like minimized electricity cost, habits, convenience, high quality and availability. To provide convenience and reduce residential electricity costs in the real-time or multi-tariff system, it is required to investigate the load/consumption patterns, customer behaviour and behavioural predictability to develop optimal control methods, which take into account customer habits and load differences.

The inquiry of household owners and energy consumption analysis has shown low awareness about the energy consumption of loads, consumption shifting possibilities and feasibility. About $80 \%$ of household owners know that using saving bulbs and consumption shifting to the low tariff period reduces the costs. But less than $20 \%$ of people are not aware of consumption distribution between the loads like lighting, water heating etc; high and low tariff consumption distribution by loads; and investments feasibility of energy consumption shifting or energy saving devices.

In the household without energy generation units, the main cost reducing possibilities are shifting of loads and/or replacing the less efficient loads with more efficient ones. Profitability of load replacing depends on energy costs, consumption amount, investments (replacement costs), exploitation costs and lifetime of the device. The shifting profitability depends on load priorities and storage possibilities. The household consumption is not a homogenous group, the different appliances has different regimes, priorities and roles [9]. P. Kadar has divided household electrical appliances to the three groups: critical load, flexible load, autonomous flexible intelligent load.

Authors have opinion, that consumption priorities can be divided into three main groups: not shiftable (I), almost shiftable (II), and shiftable (III). Shiftable loads can be defined as loads that can be shifted from a high tariff period to a low tariff period without any investments to additional electrical or thermal energy storage systems. Shiftability is closely related to customer's needs or convenience and depends on the functional possibilities of the loads, technical characteristics and surrounding environment (including building construction). For example, living room windows on the west side of a building will reduce lighting costs. By shiftability, most loads can be divided into three priority groups:

I - cooking stoves, kitchen ventilation, coffee machines (without thermos), bathroom lighting and ventilation, TV sets, PCs with modem, home cinema and audio systems, and local lighting.

II - lighting, refrigerators, boiling kettles, coffee machines (with thermos), vacuum cleaners, electric irons, and floor heating for drying purposes.

III - water heaters, washing machines, dishwashers, and floor heating for heating purposes.

This publication is based on the PQ2010 conference publication. On the following publication is more precisely described economy and profitability calculation method. Also it describes additionally energy consumption by tariffs, and 
loads distribution by day of the week. Additionally is new shifting feasibility analysis with real time tariff.

\section{II.LOAD CLASSIFICATION AND ANALYSIS OF ENERGY CONSUMPTION PATTERNS}

The object of analysis was a 3-room $(67.4 \mathrm{~m} 2)$ apartment with four habitants ( 2 adults, 2 children). The object built in 2005 has a two-tariff energy measurement system. The high tariff period in the winter time is on the workday from 7 to 11 o'clock (on the summer time from 8 to 24 o'clock). The rest is low tariff period, including the weekend For energy consumption measurements 12 Voltcraft Energy Logger 4000 devices were used. The total measurement error was less than $5 \%$ comparing with main energy meter.

The following analysis is based on the four week measurement.

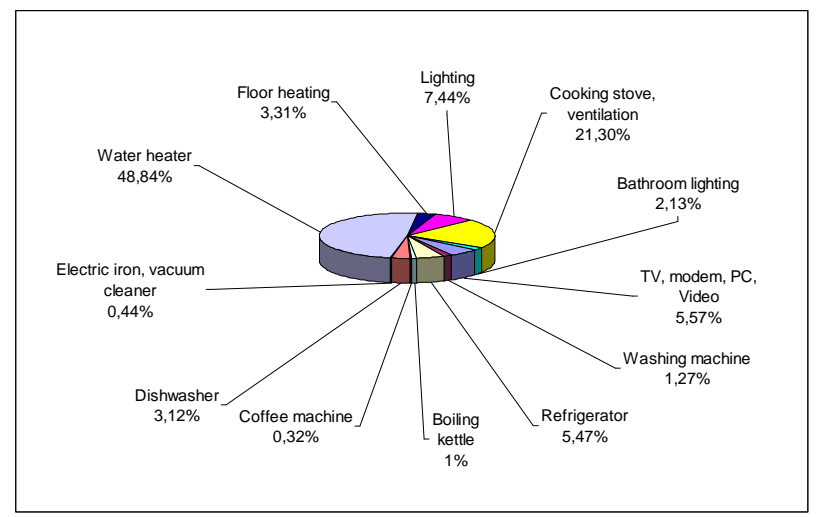

Fig. 1. Energy consumption of loads

The total energy consumption by load is shown in Fig. 1. As a result of the analysis of the customer behaviour and habits, the consuming preferences can be classified as follows.

1. Loads with shiftable consumption are water heaters, dishwashers, and washing machines - about 54\% from the total consumption.

2. Almost shiftable loads are refrigerators, boiling kettles, coffee machines, floor heating, irons, and vacuum cleaners - about $10 \%$ from the total consumption.

3. Non-shiftable loads are TV sets, PCs with a modem, home cinema and music centers, cooking stoves, kitchen ventilation, bathroom lighting and ventilation about $36 \%$ from the total consumption.

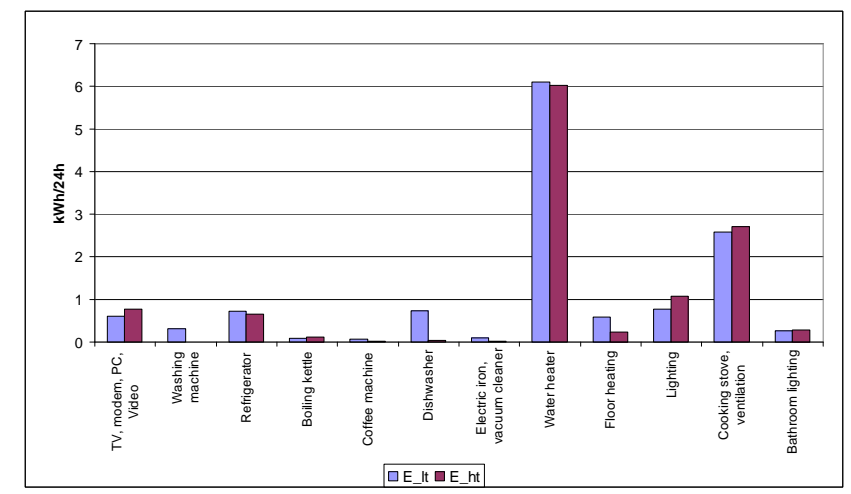

Fig. 2. Average high and low tariff energy consumption of loads
The average high tariff consumption is about $48 \%$ from the total consumption of the researched object. The average high and low tariff energy consumption of the loads is presented in Fig. 2.

Based on the customer activity or action, the three main load groups can be defined (in Fig. 3):

1. eating (refrigerators, boiling kettles, coffee machines, dishwashers, cooking stoves, and ventilation) - $31 \%$

2. hygiene (washing machines, water heaters, irons, vacuum cleaners, floor heating, and bathroom lighting) $-56 \%$

3. free-time/vacationing (lighting, TV sets, modems, PCs, video recorders, and telephone)- $13 \%$

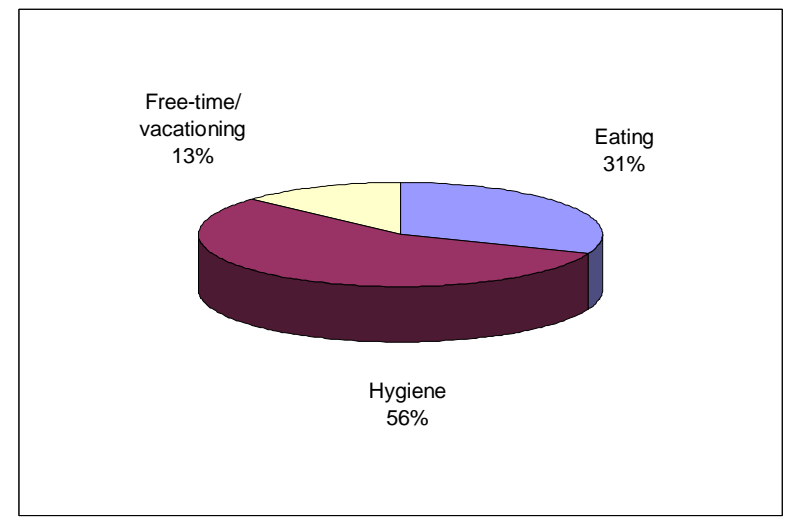

Fig. 3. Consumption by customer needs or action

\section{ANALYSIS OF TIME-DEPENDENCE OF ENERGY CONSUMPTION AND CUSTOMER BEHAVIOUR}

There are three peak hours for energy consumption:

1. the morning on the workday (from 7 to 8 o'clock)

2. the midday on the holiday ( from 12 to 14 o'clock)

3. the evening on the workday or holiday (from 19 to 21 o'clock)

Main loads, which affect the local extremums are: in the morning - water heater; in the midday - water heater and cooking stove; in the evening - water heater, cooking stove and lighting.

\section{A. Workday-energy consumption}

On the workday two local peaks can be detected: the morning and the evening. Both local extremums are located in the high tariff period and is affected mostly from water heater, cooking stove and lighting consumption. The main consumption time of water heater is between 7 to 11 and 18 to 24 . The main consumption time of cooking stove is from 17 to 21 (Fig. 5). To take into account customer comfort, energy consumption cost and consumption balancing, it is optimal to shift half of the high tariff consumption of water heater from 7 to 12 to the low tariff period between 2 and 6 o'clock and another half high tariff consumption from 18 to 23 to the high tariff period between 14 and 18 o'clock. 


\section{B. Holiday-energy consumption}

On the holiday, two local extremums can be detected: the midday and the evening. These local extremums are located in the low tariff period and are mostly caused by water heater, cooking stove and lighting consumption. The main consumption time of cooking stove and water heater is from 12 to 20 (Fig. 6). On the holiday with existing tariffs, there is no need for load shifting. From the viewpoint of homogenization/balancing the total consumption, water heater should be switched off between $12 . .16$ and $17 . . .20$ o'clock.

\section{Average energy consumption}

The average energy consumption per day is about $25 \mathrm{kWh}$. On the workday, high tariff consumption is $78 \%$ (Fig. 7). The

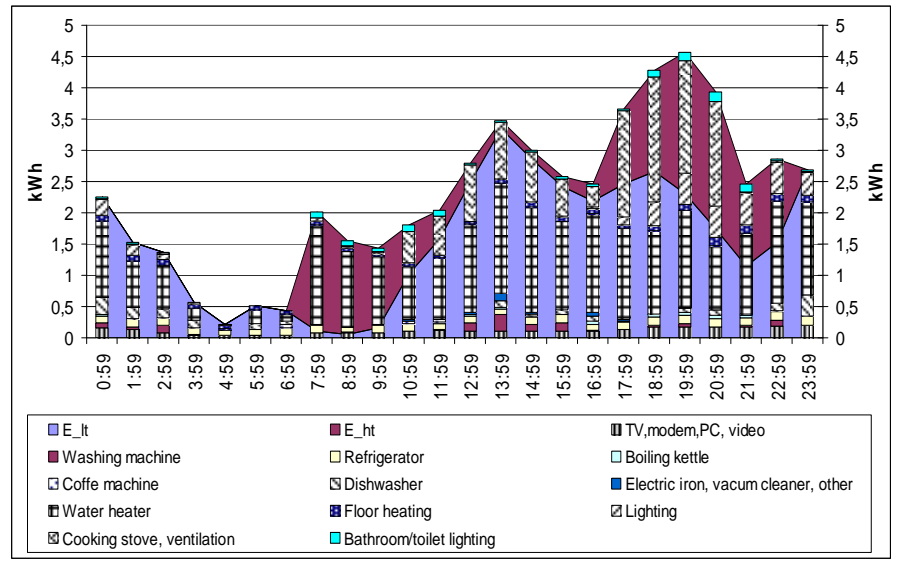

Fig. 4. Average loads and high-low tariff energy consumption distribution

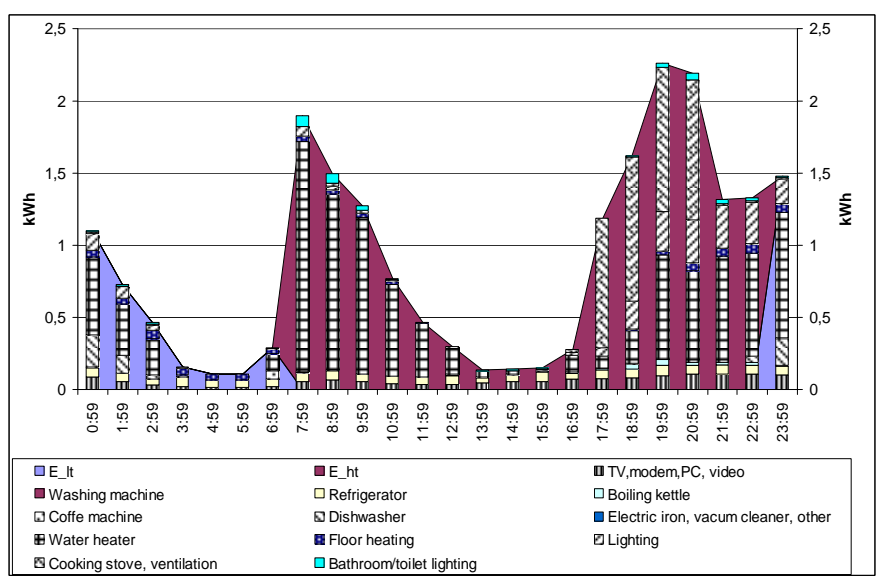

Fig. 5. Average loads and high-low tariff energy consumption distribution in the workday

\section{PROFITABILITY EVALUATION}

A universal simplified formula (1) for savings calculation in the two tariff system is the following:

$$
\begin{aligned}
& S=\left(E_{h, b}-E_{h, a}\right) \cdot p_{h}+\left(E_{l, b}-E_{l, a}\right) \cdot p_{l}= \\
& =\left(E_{h, b} \cdot p_{h}+E_{l, b} \cdot p_{l}\right)-\left(E_{h, a} \cdot p_{h}+E_{l, a} \cdot p_{l}\right)
\end{aligned}
$$

loads that mostly affect daily total consumption is water heater, cooking stove, lighting, refrigerator and TV/PC (Fig. 4).

Based on the measurements and considerations above, the main cost reduction possibilities are:

1. shifting of systems, such as water heater, floor heating, dishwasher and washing machine, from the high tariff to the low tariff period and

2. lighting energy saving by dimmering, by using presence sensors and/or more efficient lighting bulbs.

After defining cost reducing possibilities, investment costs and their feasibility should be determined.

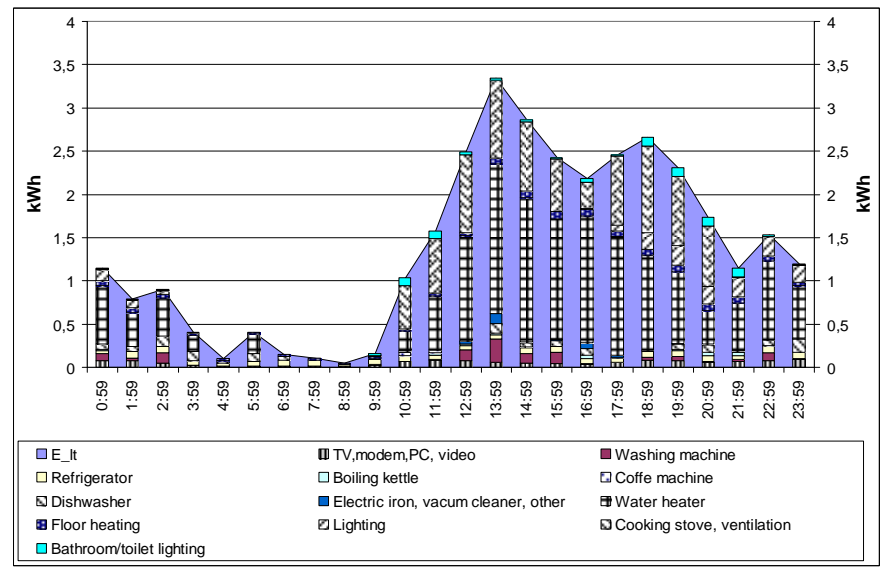

Fig. 6. Average loads and high-low tariff energy consumption distribution in the holiday

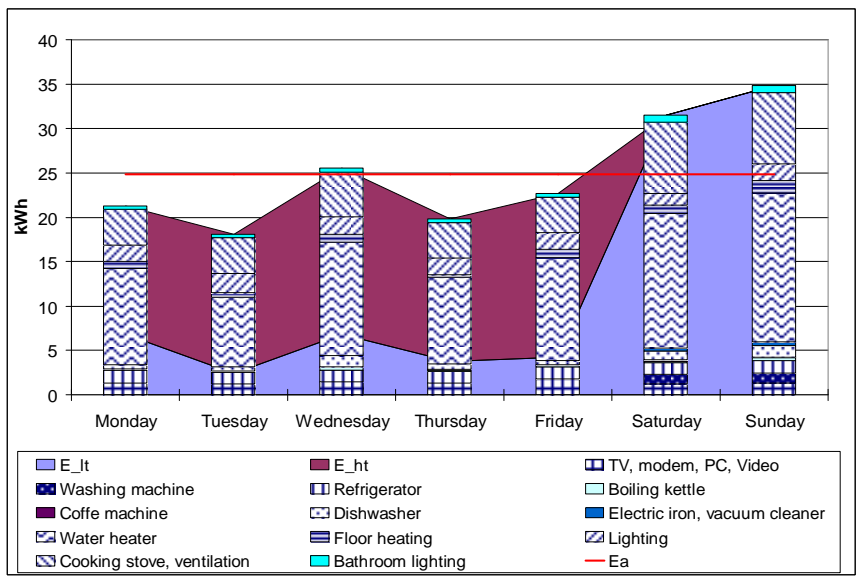

Fig. 7. Energy consumption by tariffs and loads distribution by days of the week

where $E_{h, b}$ - energy consumption before shifting or power saving at the high tariff period; $E_{l, b}$ - energy consumption before shifting or power saving at the low tariff period; $E_{h, a}$ energy consumption after shifting or power saving at the high tariff period; $E_{l, a}$ - energy consumption after shifting or power saving at the low tariff period; $p_{h}$ - high tariff price $€ / \mathrm{kWh} ; p_{l}$ low tariff price $€ / \mathrm{kWh}$. 
If $\left\{\begin{array}{l}t_{\text {cycle }}=\text { const }(\text { in hours }) \wedge p_{h}=\text { const } \wedge p_{l}=\text { const } \\ P_{h, b_{i}}, P_{h, a_{i}}, P_{l, b_{j}}, P_{l, a_{j}} \text { in Watts },\end{array}\right.$

then the following formula (3) is used for real-time energy saving calculation:

$$
S=\frac{t_{c y c l e}}{1000} \cdot\left(p_{h} \cdot \sum_{i=t_{h, 1}}^{t_{h, n}}\left(P_{h, b_{i}}-P_{h, a_{i}}\right)+p_{l} \cdot \sum_{j=t_{l, 1}}^{t_{l, m}}\left(P_{l, b_{j}}-P_{l, a_{j}}\right)\right)
$$

If the cycle time is a minute, then $t_{\text {cycle }}=1 / 60$ hours

\section{A. Profitability of consumption shifting}

In an ideal case, when $100 \%$ of the working load in the high tariff period is moved $100 \%$ to the low tariff period, the consumption costs can be reduced in Estonia up to $35 . . .36 \%$.

If $\left\{\begin{array}{l}E_{h, b}+E_{l, b}=E_{h, a}+E_{l, a} \equiv E_{\Sigma, b}=E_{\Sigma, a} \\ k_{h}=\frac{E_{h, b}}{E_{h, b}+E_{l, b}}=\frac{E_{h, b}}{E_{\Sigma, b}}=\text { const } \wedge k_{h, s}=\frac{E_{h, a}}{E_{h, b}}=\text { const } \wedge p_{h}>p_{l}\end{array}\right.$,

then $\left\{\begin{array}{l}E_{l, b}=\frac{E_{h, b}}{k_{h}}-E_{h, b} \wedge E_{h, a}=E_{h, b} \cdot k_{h, s} \wedge E_{l, a}=E_{h, b} \cdot\left(\frac{1}{k_{h}}-k_{h, s}\right) \\ S_{s}=E_{h, b} \cdot\left(1-k_{h, s}\right) \cdot\left(p_{h}-p_{l}\right)=E_{\Sigma, b} \cdot k_{h} \cdot\left(1-k_{h, s}\right) \cdot\left(p_{h}-p_{l}\right)\end{array}\right.$,

where $E_{\Sigma, b}$ - load (group) total energy consumption before shifting; $E_{\Sigma, a}$ - load (group) total energy consumption after shifting; $k_{h}$ - load high tariff consumption from total energy consumption in percent (before shifting); $k_{h, s}$ - load high tariff consumption after shifting from high tariff consumption before shifting.

Simplified formula (7) for shifting economy calculation

if $\quad \Delta p=p_{h}-p_{l} \wedge k_{s}=1-k_{h, s}=1-\frac{E_{h, a}}{E_{h, b}}=\frac{E_{h, b}-E_{h, a}}{E_{h, b}}$,

then

$$
S_{s}=E_{\Sigma, b} \cdot k_{h} \cdot k_{s} \cdot \Delta p,
$$

where $\Delta p$ - difference between high and low tariff; $k_{s}$ shifted energy from total energy consumption in percent.

Before shifting the high tariff energy consumption is about $48 \%$ from the total energy consumption, the difference between the tariffs is $0.0352 € / \mathrm{kWh}$. The computational profitability time (8) of an investment can be calculated as follows:

$t=\frac{S_{i}}{E_{h, b} \cdot k_{s} \cdot\left(p_{h}-p_{l}\right)} \Rightarrow\left\{\begin{array}{l}t_{\text {life }} \geq t, o k \\ t_{\text {life }}<t, \text { not ok }\end{array}\right.$

Consumption by water heater, washing machine, dishwasher and floor heating accounts for $56.5 \%$ from the total consumption. High tariff consumption of these devices is about $45 \%$ (annually $2295.8 \mathrm{kWh}$ ) from the total consumption. If $55 \%$ (annually $1263 \mathrm{kWh}$ ) of the consumption of these devices are removed from the high tariff to the low tariff period, the annual saving is about $44.45 €$ and profitability of $38.35 €$ investment for the shifting equipment is about ten and a half months. If the shifting equipment (water heater, floor heating) lifetime is 10 years, it can be reduced (without changes in consumption) additionally during the exploitation time up to $340 €$, which compensates all the exploitation costs (including new water heater cost) (Fig.8.). With existing tariff prices the described investment is profitable if annually $199 \mathrm{kWh}$ of the high-tariff energy consumption is shifted to the low tariff period or investment in 10 years is not higher than $444.5 €$.

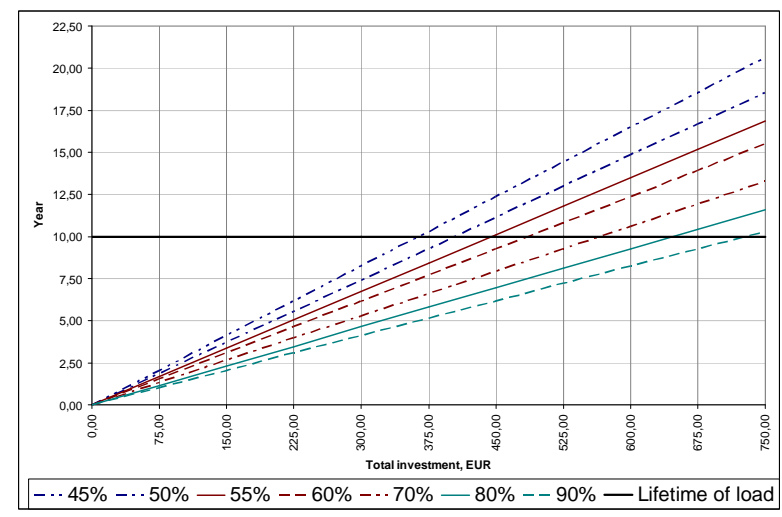

Fig. 8. Profitability by the high tariff consumption shifting to the low tariff period with a different shifting coefficient $k_{s}$ (load high tariff consumption before shifting was $45 \%$ from the total consumption).

By shifting $100 \%$ of the high tariff energy to the low tariff period the annual saving is $80.82 €$.

\section{B. Profitability of more efficient device use}

Economy by power saving depends directly on the reduced power (9).

If

$$
\left\{\begin{array}{l}
E_{h, b}+E_{l, b}>E_{h, a}+E_{l, a} \equiv E_{\Sigma, b}>E_{\Sigma, a} \\
k_{e}=\frac{E_{\Sigma, a}}{E_{\Sigma, b}}=\frac{E_{h, a}}{E_{h, b}}=\frac{E_{l, a}}{E_{l, b}}=\frac{P_{a}}{P_{b}}=\text { const } \\
k_{h}=\frac{E_{h, b}}{E_{\Sigma, b}}=\frac{E_{h, a}}{E_{\Sigma, a}}=\frac{E_{h, b}}{E_{h, b}+E_{l, b}}=\text { const } \\
p_{h}>p_{l}, t_{a}=t_{b}
\end{array},\right.
$$

then $\quad\left\{\begin{array}{l}E_{h, a}=E_{h, b} \cdot k_{e}, E_{l, a}=E_{l, b} \cdot k_{e}, E_{l, b}=\frac{E_{h, b}}{k_{h}}-E_{h, b} \\ S_{s}=E_{h, b} \cdot\left(1-k_{e}\right) \cdot\left(p_{h}-\frac{1-k_{h}}{k_{h}} p_{l}\right)= \\ =E_{\Sigma, b} \cdot\left(1-k_{e}\right) \cdot\left(k_{h} \cdot p_{h}+\left(1-k_{h}\right) \cdot p_{l}\right)\end{array}\right.$,

where $E_{\Sigma, b}$ - total energy consumption of the load before power saving; $E_{\Sigma, a}$ - total energy consumption of the load after power saving; $k_{h}$ - high tariff consumption of the load from total energy consumption in percent; $k_{e}$ - consumption after saving from consumption before the saving.

If $\quad k_{l}=1-k_{h} \wedge k_{e, s}=1-k_{e}=1-\frac{E_{h, a}}{E_{h, b}}=\frac{E_{h, b}-E_{h, a}}{E_{h, b}}$ 
Then

$$
S_{s}=E_{\Sigma, b} \cdot k_{e, s} \cdot\left(k_{h} \cdot p_{h}+k_{l} \cdot p_{l}\right)
$$

where $k_{l}$ - low tariff consumption from total consumption in percent; $k_{e, s}$ - saved energy from total consumption before the saving. If consumption and consumption time after the investment stays similar to that before the investment, the simplified formula (13) is as follows:

$$
S=Q_{b} \cdot\left(1-\frac{P_{a}}{P_{b}}\right),
$$

where $P_{b}$ - installed power before load exchange, $P_{a}$ - total power after load exchange, $Q_{b}$ - cost before the load exchange (before power saving). The following formula (14) and figure show the calculation of the profitability time of the investment costs of a saving bulb.

$$
t=\frac{S_{i}}{E_{\Sigma, b} \cdot\left(1-k_{e}\right) \cdot\left(k_{h} \cdot p_{h}+\left(1-k_{h}\right) \cdot p_{l}\right)} \Rightarrow\left\{\begin{array}{l}
t_{\text {life }} \geq t, o k \\
t_{\text {life }}<t, \text { not ok }
\end{array}\right.
$$

Today lighting takes $7.4 \%$ from the total consumption. If halogen bulbs $(15 \times 40 \mathrm{~W})$ are changed to the saving bulbs (type G-9, $15 \times 9 \mathrm{~W}$ ), the annual saving is about $42.25 €$ and profitability of $72 €(15 \times 4.8 €)$ investment is about 1 year 8 months. If habits do not change, lifetime of a saving bulb is approximately 2 years and 8 months (Fig. 9.), which makes an additional profit of $42.25 €$. With existing customer habits (lighting high-tariff consumption 58.7\%) and tariff prices, a 72 $€$ investment is profitable if the investment to one saving bulb is not higher than $7.67 €$.

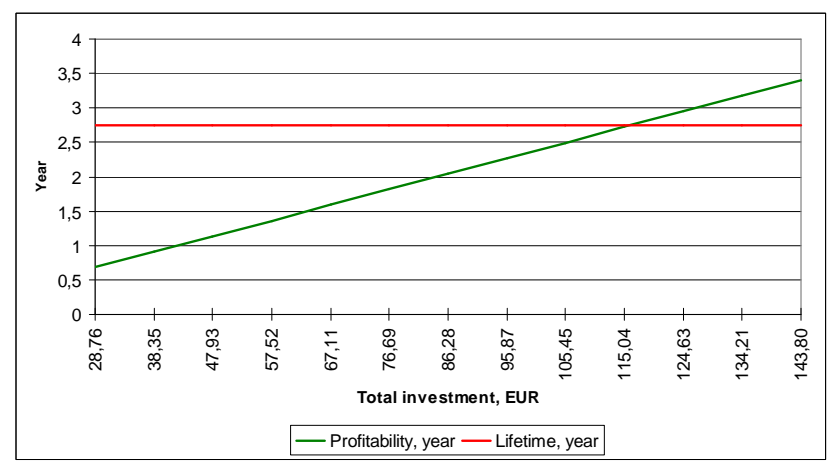

Fig. 9. Profitability of investment to saving bulbs

The stand-by consumption includes TV, video, modem, PC, washing machine, dishwasher and wireless phone. The annual stand-by consumption is about $701 \mathrm{kWh}(80 \mathrm{~W} / \mathrm{h})$, i.e. additional annual saving possibilities in the consumption costs about $56.4 €$.

\section{Shifting feasibility with real-time or multi tariff}

Usage of real-time tariff system makes micro generation units more profitable (and reduce investment risks), but the profitability of customer's investments to the complex (intelligent) shifting equipment with real-time tariff is questionable. The reason is that the difference between maximum and minimum tariffs in the real-time tariff system is not known. What is the optimal tariff changing frequency and customer response time in the real-time tariff system? The profitability of the energy management system depends directly on these parameters. On the demand side it needs more investments for more sophisticated power (or energy) management systems (including control and energy storage systems). Today the energy management systems with AC/AC converters or without DC-bus and storage batteries for shifting are not profitable. The alternative is to use the storage systems with DC converters in the households, which are cheaper, but profitability depends highly on the shifting system manufacturer and functionality of load. The profitability of the storage systems depends also on the real-time tariff changing frequency. For example, fast changes in the real-time tariffs mean additional investments to supply system and/or grid (current peaks on the lower tariff period) and/or more expensive storage systems (fast charging storage batteries).

Based on Fig. 5 and 6 the average workday consumption per hour is $0.9 \mathrm{~kW}$, and average holiday consumption per hour is $1.4 \mathrm{~kW}$. If lighting equipment is replaced with more efficient devices and water heater consumption is shifted with timer or by real-time price based control algorithm to low tariff period, the daily electricity consumption of high tariff period will be about $5 \ldots 7 \mathrm{kWh}$ with peak power $5 \ldots 7 \mathrm{~kW}$. Price of such shifting equipment (UPS) is at least $3000 €$. Based on difference of low and high tariff electricity prices and UPS-system life-time and prices, today such systems are not profitable. To guarantee the feasibility of UPS-system, it should be at least 15 times cheaper, or low and high tariff difference should be increased at least 10 times.

\section{V.CONCLUSION}

The main reason to change the habits is the net profit. Investments to more efficient systems are not feasible if the lifetime of these systems is equal to or shorter than the profitability time. Today the investments to the load shifting are smaller (and shifting functionality is already integrated to many household systems), profitability time is at least 1.5 times shorter (including higher net profit) than investments to power saving.

Investments to shifting and energy saving devices are approximately $110 €$ and total annual savings after investments are $86.7 €(12 \%$ from total consumption costs), which results in investment profitability of about 1 year, 3 months and one week.

The high tariff energy consumption on the workday by shifting and using of saving bulbs is reduced from $78 \%$ to $53 \%$. The total high-tariff energy consumption by shifting and using of saving bulbs is reduced from $48 \%$ to the $32 \%$ (Fig. 10). Total energy consumption is reduced to $5.6 \%$.

Small investments, to saving bulbs, timers or presence sensors are profitable within $1 . . .2$ years. With existing tariffs system, it is no needs to expensive scheduling or power management systems.

Customers with higher energy consumption or more storage capacities integrated to the system will be provided more saving possibilities. Small investments, to saving bulbs, timers 
or presence sensors are profitable within $1 . . .2$ years. With existing two-tariff system, it is no needs to expensive scheduling or power management systems.

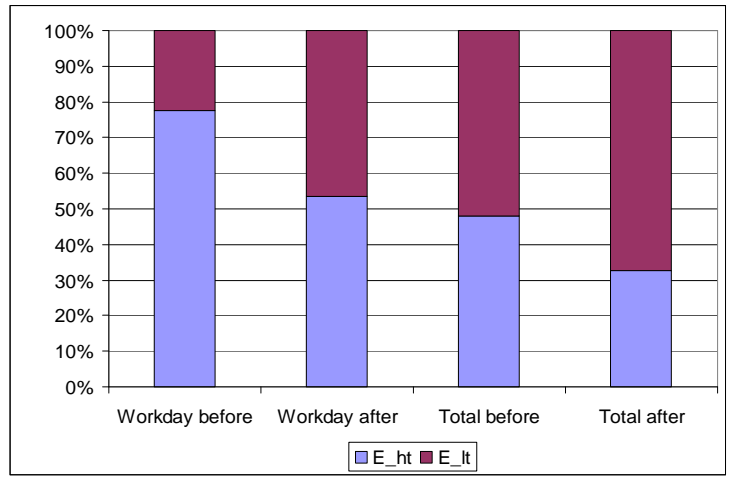

Fig. 10. Low and high tariff energy consumption before and after changes

Based on these considerations the paper gives some suggestions for energy saving or shifting and future views for household product development:

- $\quad$ instead of PC should be used accumulator integrated laptop PCs;

- boiling kettle and coffee machine with thermos functionality;

- $\quad$ accumulators integrated LED-lighting for consumption shifting;

- division of bathroom/toilet/cellar and other similar lighting on two independent groups (an manually controlled emergency lighting group and another automatically controlled lighting group with presence sensor);

- using of appliances with scheduling functionality and/or remotely controllable power converters;

- in new buildings using on the household switchboard level DC-bus and on the feeders instead of MCBs the intelligent power $\mathrm{AC} / \mathrm{DC}$ and $\mathrm{DC} / \mathrm{AC}$ converters.

The research work continues and analyses of about 100 households have been planned in 2010-2011.

\section{ACKNOWLEDGEMENT}

Authors thank Estonian Ministry of Education and Research (Tallinn University of Technology Grant No BF123, BF124, B613A) for financial support of this study.

\section{REFERENCES}

[1] U.S. Department of Energy, Energy Efficiency and Renewable Energy, 2008 Buildings Energy Data Book: Mar. 2009.

[2] Energy Conservation Committee Report and Recommendations, Reducing Electricity Consumption in Houses, Ontario Home Builders' Association, May 2006.

[3] Mohsenian-Rad A., Vincent W.S. W., Jatskevich J., Schober R, Optimal and Autonomous Incentive-based- Energy Consumption Scheduling Algorothm for Smart Grid, Innovative Smart Grid Technologies (ISGT), p: $1-6,19-21$ Jan. 2010.

[4] Handa T., Oda A., Tachikawa, T., Watanabe Y., Ichimura, J., Nishi, H., Table-based scheduling method for distributed demand side management, Industrial Electronics, 34th Annual Conference of IEEE, IECON 2008, pp:2748 - 2753. 10-13 Nov. 2008.
[5] Mauri G., Moneta D, Gramatica P., Automation systems to support smart energy behaviour of small customers, CIRED Seminar 2008 SmartGrids for Distribution, Frankfurt, 23-24 June 2008.

[6] Majid, M.S., Rahman, H.A., Hassan, M.Y., Ooi, C.A., Demand Side Management Using Direct Load Control for Residential Research and Development, 2006. SCOReD 2006. 4th Student Conference on 27-28 June 2006, pp. 241 - 245

[7] Molderink, A., Bakker, V., Bosman, M.G.C., Hurink, J.L., Smit, G.J.M., A three-step methodology to improve domestic energy efficiency Innovative Smart Grid Technologies (ISGT), Publication Year: 2010, pp: $1-8$.

[8] Molderink, A., Bakker, V., Bosman, M.G.C.; Hurink, J.L.; Smit, G.J.M., Domestic energy management methodology for optimizing efficiency in Smart Grids, PowerTech, 2009 IEEE Bucharest Publication Year: 2009, Page(s): 1 - 7.

[9] Kadar P., ZigBee controls the household appliances; Intelligent Engineering Systems, 2009. INES 2009. International Conference on Publication Year: 2009, Page(s): 189 - 192

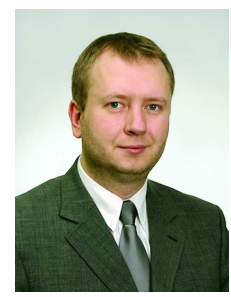

Argo Rosin received the Dipl.Eng, M.Sc. and Dr.Sc.techn. degrees in electrical engineering from Tallinn University of Technology, Tallinn, Estonia, in 1996, 1998 and 2005, respectively. He is presently a Senior Researcher in the Department of Electrical Drives and Power Electronics, Tallinn University of Technology. He has published more than 40 papers on energy management, control and diagnostic systems development and is the holder of an Patent in this application field. His research interests include modeling and simulation of power management and industrial control systems. He is member of Estonian Association of Engineers, Estonian Association of Transport and Roads.

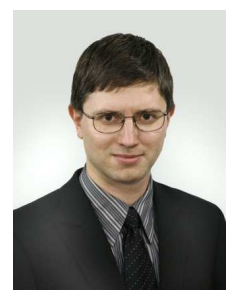

Taavi Möller received the B.Sc and M.Sc degrees in electrical engineering from Tallinn University of Technology, Tallinn, Estonia, in 2001 and 2004, respectively. At the present time he is a researcher in the Department of Electrical Drives and Power Electronics. He has over 10 publications in the field of electrical drives, power electronics and information technology. His research interests include flexible automation systems (remote control of electrical drives), SmartGrid Technology and its Applications in Estonian Power System.

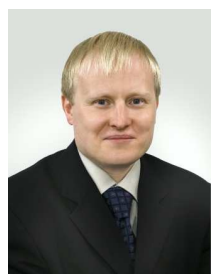

Madis Lehtla received the Dipl.Eng, M.Sc. and Dr.Sc.techn. degrees in electrical engineering from Tallinn University of Technology, Tallinn, Estonia, in 1998, 1999 and 2006, respectively. He is presently a Senior Researcher in the Department of Electrical Drives and Power Electronics, Tallinn University of Technology. He has over 30 publications and owns two Utility Models in the field of power electronics and electrical drives. His research interests are in digital control of switching power converters, including modelling, design, and simulation.

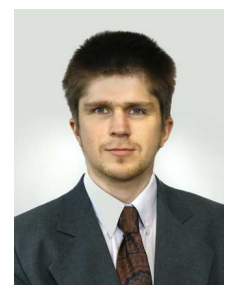

Hardi Hõimoja received the Dipl.Eng degree in electrical engineering from Tallinn University of Technology, Tallinn, Estonia, in 1998, respectively. At the end of 2009 he defended the PhD Thesis devoted to energy efficiency estimation and energy storage calculation methods for industrial applications. At the present time he is a researcher in the Department of Electrical Drives and Power Electronics. He has over 20 publications and owns a Utility Model in the field of electrical drives and power electronics. 